\title{
Analysis of the Epitope Structure of Plum pox virus Coat Protein
}

\author{
Thierry Candresse, Pilar Saenz, Juan Antonio García, Donato Boscia, \\ Milan Navratil, Maria Teresa Gorris, and Mariano Cambra
}

First author: Equipe de Virologie, UMR 1332 de Biologie du Fruit et Pathologie, INRA, Université de Bordeaux, BP81, 33883 Villenave d'Ornon Cedex, France; second and third authors: Centro Nacional de Biotecnología (CNB), CSIC, Campus Universidad Autónoma, 28049 Madrid; fourth author: Istituto di Virologia Vegetale del CNR, Sezione di Bari, Via Amendola 165/A, 70126 Bari, Italy; fifth author: Palacky University in Olomouc, Faculty of Science, Slechtitelu 11, Olomouc 783 71, Czech Republic; and sixth and seventh authors: Centro de Protección Vegetal y Biotecnología. Instituto Valenciano de Investigaciones Agrarias (IVIA), Carretera MoncadaNáquera km 5, 46113 Moncada, Valencia, Spain.

Current address of P. Saenz: Progenika Biopharma S.A. Edificio 801, Parque Tecnológico de Bizkaia 48160 Derio, Spain. Accepted for publication 9 December 2010.

\section{ABSTRACT}

Candresse, T., Saenz. P., García, J. A., Boscia, D., Navratil, M., Gorris, M. T., and Cambra, M. 2011. Analysis of the epitope structure of Plum pox virus coat protein. Phytopathology 101:611-619.

Typing of the particular Plum pox virus (PPV) strain responsible in an outbreak has important practical implications and is frequently performed using strain-specific monoclonal antibodies (MAbs). Analysis in Western blots of the reactivity of 24 MAbs to a 112-amino-acid N-terminal fragment of the PPV coat protein (CP) expressed in Escherichia coli showed that 21 of the 24 MAbs recognized linear or denaturation-insensitive epitopes. A series of eight C-truncated CP fragments allowed the mapping of the epitopes recognized by the MAbs. In all, 14 of them reacted to the $\mathrm{N}$-terminal hypervariable region, defining a minimum of six epitopes, while 7 reacted to the beginning of the core region, defining a minimum of three epitopes. Sequence comparisons allowed the more precise positioning of regions recognized by several MAbs, including those recognized by the 5B-IVIA universal MAb (amino acids 94 to 100) and by the 4DG5 and 4DG11 D serogroup-specific MAbs (amino acids 43 to 64). A similar approach coupled with infectious cDNA clone mutagenesis showed that a V74T mutation in the N-terminus of the $\mathrm{CP}$ abolished the binding of the M serogroup-specific AL MAb. Taken together, these results provide a detailed positioning of the epitopes recognized by the most widely used PPV detection and typing MAbs.

Additional keyword: Sharka
Plum pox virus (PPV), the agent of the Sharka disease of stone fruits (peach, apricot, plum, ...), is the most detrimental virus affecting these crops $(5,19,40)$ and is currently listed as a quarantine pathogen by most countries in the world. PPV is one of the best known potyviruses, with a wealth of information available, in particular, on its variability and on the existence of several strains. The majority of PPV isolates identified to date belong to one of two major strains, PPV-D or PPV-M $(6,9)$, or to a strain resulting from a recombination between these two parent strains (PPV-Rec) (23). Several minor strains have also been identified, each represented by a limited number of isolates thus far: the El Amar (PPV-EA) (48), Cherry (PPV-SoC) $(37,38) \mathrm{W}$ (PPV-W) (29), and T (PPV-T) (45) strains. The discrimination between PPV strains is based on phylogenetic analyses and, therefore, on sequence differences. The coat protein $(\mathrm{CP})$ sequence has been extensively used to discriminate PPV strains but other regions of the genome can also be used $(22,23)$.

PPV strains appear to have different biological properties or behavior in the field $(6,8)$, with potential implications for the development of PPV epidemics and, therefore, for Sharka management. Therefore, the precise identification of the strain responsible for an outbreak is required by many national regulations. Typing is generally achieved using polymerase chain reaction (PCR)-based approaches, such as strain-specific PCR assays $(8,39)$, or using monoclonal antibodies (MAbs) (4). Many

Corresponding author: T. Candresse; E-mail address: tc@ bordeaux.inra.fr

doi:10.1094/PHYTO-10-10-0274

C 2011 The American Phytopathological Society
MAbs have been developed against PPV (2,3,16,28,34-36), and comparison of their reactivity toward a range of molecularly typed isolates led to the identification of a single MAb able to recognize all PPV isolates (MAb 5B-IVIA) $(1,3,4)$ and of MAbs showing very good but not absolute specificity for isolates of the PPV-D or PPV-M strains (1-4,7). Despite this accumulated knowledge, there is currently only limited information on the types and distribution of epitopes on the PPV CP and no information on the identity of the epitopes recognized by the widely used PPV-specific 5B-IVIA MAb or by strain-specific MAbs. Previously, Fernández-Fernández et al. (20) identified a number of immunogenic hotspots or preferential recognition sites (PRS) in the PPV CP using polyclonal antisera reactivity to short overlapping synthetic peptides (peptide scanning or PEPSCAN). Four of these were located in the N-terminal variable region of the $\mathrm{CP}$, seven in the conserved core, and a single one in the variable C-terminal end. Similarly, PEPSCAN analysis has been used to identify binding regions for eight MAbs specific for the PPV-W strain and two MAbs with broader but incomplete reactivity toward PPV strains (16).

Extensive or significant antigenic studies are available for several other potyviruses, including Johnsongrass mosaic virus (42,43), Zucchini yellow mosaic virus (ZYMV) (18,33), Clover yellow vein virus (27), Potato virus $Y$ (14), or Bean yellow mosaic virus $(24,25)$. These studies used different strategies to identify specific epitopes, including PEPSCAN analysis $(18,43)$ or the use of CP or CP derivatives expressed in Escherichia coli $(14,25,33)$, often in conjunction with $\mathrm{CP}$ sequence comparison between isolates showing differential reactivity. The general picture of potyvirus antigenicity which emerges is that epitopes with narrow specificity or virus-specific epitopes are located on the surface- 
exposed $\mathrm{N}$ - and $\mathrm{C}$-terminal variable regions of the $\mathrm{CP}$ (42), while epitopes showing broad specificity and allowing the recognition of different viral species are located in the conserved internal core of the $\mathrm{CP}(31,43)$. In addition, the $\mathrm{CP} \mathrm{N}$-terminal region appears to be immunodominant (43).

In this report, we identified regions of the PPV CP recognized by a number of PPV-specific MAbs, using 24 MAbs and a panel of PPV CP fusion proteins expressed in E. coli in combination with information on reactivity of a range of PPV isolates and sequence comparisons. These results pinpoint the sites reacting with the strain-specific MAbs or with the only PPV-specific MAb so far known to detect all PPV isolates. Preliminary and partial information on this research had been reported (10) and the results presented here narrow down the position of the various epitopes while, in many cases, identifying point mutations that directly affect the binding of the various MAbs. The peptide sequences identified in this work as recognized by the universal 5B-IVIA and PPV-M-specific AL MAbs have been patented (patent number P201000347, March 2010).

\section{MATERIALS AND METHODS}

Virus isolates and MAbs. A PPV-D field isolate from Spain (isolate Llutxent 37-2) and a PPV-M isolate held in collection at INRA Bordeaux (PPV-10) were used to generate the PPV-D or PPV-M fusion proteins used in this study. With the exception of MAb 4B1D5 (INRA, Bordeaux, France), obtained following immunization with a PPV-M isolate, and MAb AL (CNR, Bari), raised against a PPV-D plus PPV-M mixture, all the MAbs used had been independently obtained following immunization with isolates belonging to the PPV-D strain (Table 1). The MAbs were used in Western blot experiments at the concentration optimized for their use in triple-antibody sandwich (TAS) enzyme-linked immunosorbent assay (ELISA), also known as double-antibody sandwich indirect ELISA (Table 1). In addition, three polyclonal antisera obtained at INRA Bordeaux were also used (Table 1). One rabbit antiserum was raised against purified $E$. coli maltosebinding protein (MBP), which is expressed from the pMal-C2 cloning vector (New England Biolabs). The two other antisera, PPV no. 100 and PPV no. 137, were obtained following immunization of rabbits with purified PPV particles of isolates belonging to the PPV-D and PPV-M strains, respectively.

Expression of PPV CP fragments as MBP fusion proteins in E. coli. A 467-bp cDNA fragment corresponding to the 43 C-terminal amino acids of the NIb protein and 112 amino acids (aa) from the $\mathrm{N}$-terminal part of the CP (comprising the 92-aalong N-terminal variable part and the first 20 aa of the conserved core) was amplified by reverse-transcription (RT)-PCR using primers $\mathrm{P} 4 \mathrm{~b}$ and $\mathrm{P} 3 \mathrm{D}$ (7) for the Llutxent $37-2$ isolate and primers P4b and P3M (5' ACATAGCAGAGACGGCACTC 3') for the PPV-10 isolate, respectively. PCR conditions were those reported by Candresse et al. (7). The amplified fragments were purified by agarose gel electrophoresis and ligated in the SmaI site of pJK$\mathrm{Km}$ plasmid (32). Identity and integrity of the cloned PCR fragments was verified by sequencing and the cDNAs, excised from the pJK-Km vector using Bam HI and EcoRI digestion, were subcloned in BamHI-EcoRI cut pMal-C2 expression vector (New England Biolabs). In this way, plasmids pMCL37-2 (PPV-D strain, Llutxent 37-2 cDNA) and pMCM-5 and pMCM-10 (PPV$\mathrm{M}$, two different PPV-10 cDNAs differing by a point mutation and identified during sequence confirmation of the constructs) were obtained and their sequence again verified. The PPV cDNA sequences were inserted in frame, downstream of the E. coli MBP gene, thus providing for the expression of the PPV polypeptide as a C-terminal fusion to the MBP.

Construction of a series pMCL37-2 derivatives allowing the expression of C-terminally truncated MBP-CP fusion proteins. The PPV cDNA inserted in pMCL37-2 (GenBank accession number EU729745) was subjected to recurrent deletion using an exonuclease III-based kit (Erase-a-base; Promega Corp.). Eight recombinant plasmids were obtained, named $\mathrm{p} \Delta 1$ to $\mathrm{p} \Delta 8$, and their coding capacity verified by sequencing. The $\mathrm{p} \Delta 1$ to $\mathrm{p} \Delta 8$ vectors direct the expression of fusion proteins containing the first $108,102,89,71,64,48,43$, and 30 aa, respectively, of the PPV CP (Fig. 1).

Western blot analysis of the MAbs reactivity toward the MBP-CP fusion proteins. Induction of the synthesis of the various fusion proteins was performed as recommended by New England Biolabs. Briefly, exponential phase cultures of E. coli cells containing the appropriate vectors were induced by the

TABLE 1. Name, laboratory of origin, form, and work dilution of the various polyclonal and monoclonal antibodies (MAbs) used in this study

\begin{tabular}{|c|c|c|c|}
\hline Name & Origin & Provided as & Working dilution \\
\hline Anti PPV-D no. 100 & INRA Bordeaux & Polyclonal antiserum & $1 / 5,000$ \\
\hline Anti PPV-M no. 137 & INRA Bordeaux & Polyclonal antiserum & $1 / 5,000$ \\
\hline Anti MBP & INRA Bordeaux & Polyclonal antiserum & $1 / 5,000$ \\
\hline 4DB12 & IVIA Valencia & Purified MAb & $0.1 \mu \mathrm{g} / \mathrm{ml}$ \\
\hline 1EB6 & IVIA Valencia & Purified MAb & $0.1 \mu \mathrm{g} / \mathrm{ml}$ \\
\hline 4DG5 & IVIA Valencia & Purified MAb & $0.1 \mu \mathrm{g} / \mathrm{ml}$ \\
\hline 4DG11 & IVIA Valencia & Purified MAb & $0.02 \mu \mathrm{g} / \mathrm{ml}$ \\
\hline 5B-IVIA & IVIA Valencia & Purified MAb & $0.1 \mu \mathrm{g} / \mathrm{ml}$ \\
\hline 4DB7 & IVIA Valencia & Purified MAb & $0.1 \mu \mathrm{g} / \mathrm{ml}$ \\
\hline $4 \mathrm{~F} 4$ & IVIA Valencia & Purified MAb & $0.2 \mu \mathrm{g} / \mathrm{ml}$ \\
\hline $3 \mathrm{C} 6$ & IVIA Valencia & Purified MAb & $0.1 \mu \mathrm{g} / \mathrm{ml}$ \\
\hline $4 \mathrm{CB} 1$ & IVIA Valencia & Purified MAb & $0.2 \mu \mathrm{g} / \mathrm{ml}$ \\
\hline $\mathrm{AL}$ & CNR Bari & Ascites fluid & $1 / 1,000$ \\
\hline B7C4 & ISPAVE Roma & Ascites fluid & $1 / 25,000$ \\
\hline G10F8 & ISPAVE Roma & Ascites fluid & $1 / 25,000$ \\
\hline 4B1D5 & INRA Bordeaux & Ascites fluid & $1 / 5,000$ \\
\hline 4H7G4 & INRA Bordeaux & Ascites fluid & $1 / 5,000$ \\
\hline 4F4G11 & INRA Bordeaux & Ascites fluid & $1 / 5,000$ \\
\hline 2D2D4 & INRA Bordeaux & Cell culture supernatant & $1 / 10$ \\
\hline $4 \mathrm{C} 5 \mathrm{H} 8$ & INRA Bordeaux & Cell culture supernatant & $1 / 10$ \\
\hline 2D2D7 & INRA Bordeaux & Cell culture supernatant & $1 / 10$ \\
\hline 03 & RIVGB Olomouc & Purified MAb & $0.5 \mu \mathrm{g} / \mathrm{ml}$ \\
\hline 04 & RIVGB Olomouc & Purified MAb & $2 \mu \mathrm{g} / \mathrm{ml}$ \\
\hline 06 & RIVGB Olomouc & Purified MAb & $0.3 \mu \mathrm{g} / \mathrm{ml}$ \\
\hline 07 & RIVGB Olomouc & Purified MAb & $2 \mu \mathrm{g} / \mathrm{ml}$ \\
\hline 08 & RIVGB Olomouc & Purified MAb & $0.5 \mu \mathrm{g} / \mathrm{ml}$ \\
\hline $4-11$ & RAC Changins & Conjugated MAb & $1 / 50$ \\
\hline
\end{tabular}


addition of $0.3 \mathrm{mM}$ isopropyl-thio-galactopyranoside (IPTG). Following a 1.5 -h incubation at $37^{\circ} \mathrm{C}$ with vigorous shaking, cells were harvested by centrifugation $\left(3 \mathrm{~min}\right.$ at $13.000 \mathrm{rpm}, 4^{\circ} \mathrm{C}$ ). Cells were resuspended directly in denaturing polyacrylamide gel electrophoresis (PAGE) loading buffer (125 mM Tris- $\mathrm{HCl}[\mathrm{pH}$ 6.8 ], $10 \%$ sodium dodecyl sulfate [SDS] and 25\% $\beta$-mercaptoethanol) and lysed by boiling for $5 \mathrm{~min}$. Protein extracts were clarified (10 min of centrifugation at $13.000 \mathrm{rpm}$ ) and either used directly or stored at $-20^{\circ} \mathrm{C}$ until used. Protein samples were separated on $10 \%$ PAGE gels and transferred by semi-dry blotting on nitrocellulose membranes (Hybond C Amersham or BA85 Schleicher \& Schuell). Following a rapid staining of the membranes with Ponceau Red, the membranes were saturated by a 1-h incubation in RIA buffer (10 mM Tris- $\mathrm{HCl}$ [pH 7.5], $160 \mathrm{mM}$ $\mathrm{NaCl}, 0.1 \%$ SDS, $0.5 \%$ sodium deoxycholate, and $1 \%$ Triton $\mathrm{X} 100)$ supplemented with $1 \%$ gelatin. The membranes were then incubated for $2.5 \mathrm{~h}$ in RIA buffer plus gelatin containing appropriate concentrations of MAbs or polyclonal antisera. Following three 5-min washes in RIA buffer, the membranes were then incubated for $2 \mathrm{~h}$ in RIA buffer plus gelatin containing anti-mouse or anti-rabbit immunoglobulin $\mathrm{G}$ alkaline phosphatase-conjugated goat immunoglobulins (1:5.000 dilution; Sigma-Aldrich). The membranes were washed again three times in RIA buffer, equilibrated in phosphatase reaction buffer $(100 \mathrm{mM}$ Tris- $\mathrm{HCl}[\mathrm{pH}$ 9.5], $100 \mathrm{mM} \mathrm{NaCl}$, and $5 \mathrm{mM} \mathrm{MgCl}$ ). Detection was performed by incubating the membrane in phosphatase reaction buffer supplemented with nitroblue tetrazolium at $75 \mu \mathrm{g} / \mathrm{ml}$ and 5-bromo-4chloro-3 indolyl phosphate at $50 \mu \mathrm{g} / \mathrm{ml}$. The reaction was stopped by rinsing the membranes in water and drying them.

Analysis of the reactivity of selected PPV isolates toward MAbs. PPV isolates were propagated in GF305 peach seedlings or in Nicotiana benthamiana plants in a level 3 biosafety containment greenhouse. The reactivity of the PPV isolates toward the MAbs was determined in TAS-ELISA as reported previously (7). Detection with anti-PPV polyclonal reagents in a double-antibody sandwich ELISA was performed in parallel, in order to confirm the infection status of the plant material used.

Sequencing of the $\mathrm{N}$-terminal $\mathrm{CP}$ region of $\mathrm{PPV}$ isolates and sequence comparisons. The genomic sequence corresponding to amino acids 1 to 112 of selected PPV isolates was determined as reported by Candresse et al. (7), following amplification with the $\mathrm{P} 3 \mathrm{D}-\mathrm{P} 4 \mathrm{~b}$ or $\mathrm{P} 3 \mathrm{M}-\mathrm{P} 4 \mathrm{~b}$ primer pairs. Multiple alignments of partial PPV CP amino acid sequences were performed using the ClustalX program (44), using sequences determined in this work, published sequences, and sequences present in databanks. Consensus sequences were determined manually for the PPV-D and PPV-M strains using ClustalX generated alignments corresponding to 58 and 32 distinct sequences, respectively.

Construction and analysis of an infectious PPV-M strain isolate with a mutated CP. Based on sequence comparisons, the V74D mutation which replaces the valine at position 74 of PPV $\mathrm{CP}$ by an aspartic acid was identified as potentially affecting MAb AL reactivity. It was introduced in a PPV-M isolate using the pGPPVR/P308 PPV full-length infectious cDNA clone. This construct consists of the first 5' 308 nucleotides of PPV-Rankovik (D strain) followed by nucleotides 309 to 9,786 of PPV-PS (M strain) (12,13). The mutation was created using the PCR-based mutagenesis method of Herlitze and Koenen (26). A first PCR was done using pGPPVR/P308 as template and oligo $267\left(5^{\prime}\right.$ GAACTGTGGTTTATGTC $3^{\prime}$ ) and the mutator oligonucleotide $5^{\prime}$ TTCCATAATCTCCAAAAG $3^{\prime}$ (the mutated nucleotide is in bold) as primers. The second PCR was carried out using the product of the first PCR and a BstBI (PPV nucleotide 8,376)-XbaI (in the polylinker at the end of the PPV sequence) fragment from pGPPVR/P308 as template, and oligo 267 and oligo $55\left(5^{\prime}\right.$ CTATGCACCAAACC $3^{\prime}$ ) as primers. The product of this second PCR was digested with Eco88I (PPV nucleotide 8,257) and SacI (PPV nucleotide 9,021) and inserted, together with an SalI-Eco88I (PPV nucleotides 7,633 to 8,257) fragment from pGPPVR/P308, between the SalI and SacI cloning sites of pUC19. Finally, an SalI-SacI (PPV nucleotides 7,631 to 9,021) from the resulting plasmid carrying the mutation was ligated with the BglI-SalI and SacI-BglI fragments from pGPPVR/P308, giving rise to pGPPVPSV74D. Following in vitro transcription of the mutated construct with the T7 Cap-Scribe kit (Roche), plants were rub inoculated as described (41) and the stability of the introduced mutation verified by sequencing of a cDNA fragment amplified from the viral progeny by immunocapture RT-PCR (47). Reactivity of the mutated isolates toward selected MAbs was determined as described above.

\section{RESULTS}

Expression of partial PPV CP fragments as MBP fusion proteins in $E$. coli and analysis of their reactivity toward polyclonal and monoclonal anti-PPV antibodies. Partial cDNA fragments encoding the last $43 \mathrm{C}$-terminal amino acids of the $\mathrm{NIb}$ protein and the first 112 aa of the $\mathrm{CP}$ of two PPV isolates

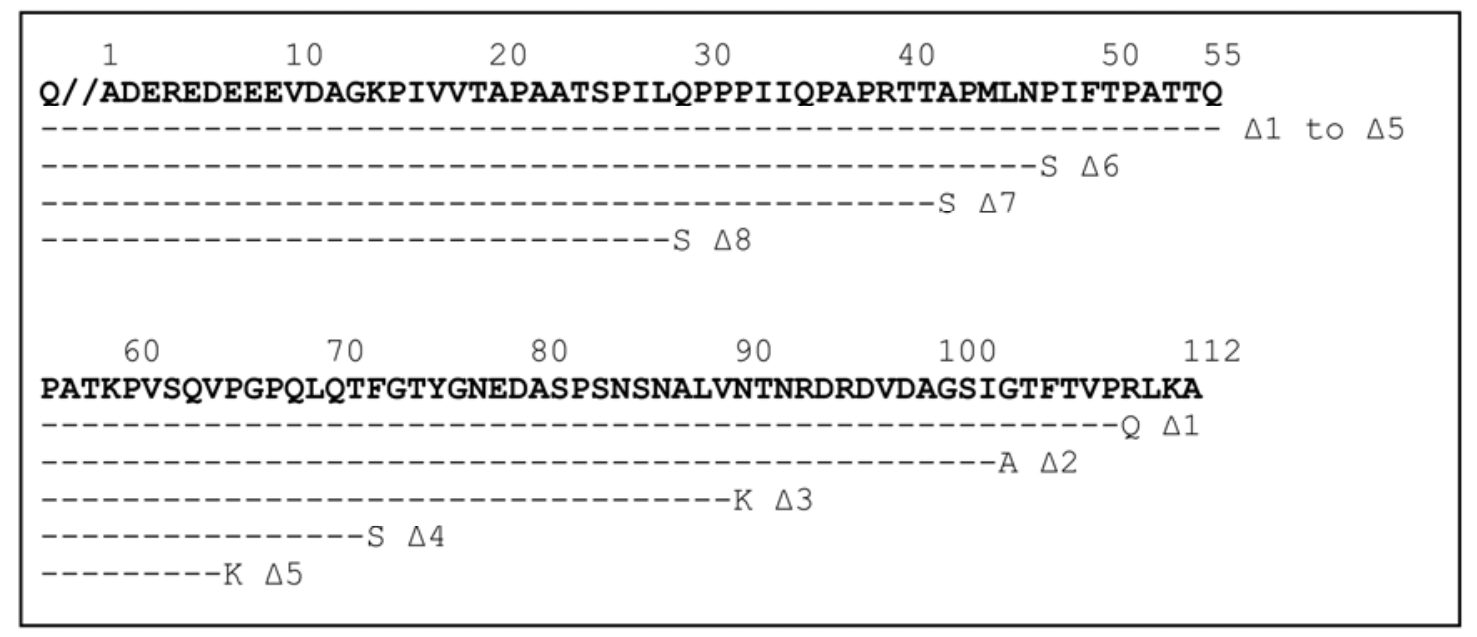

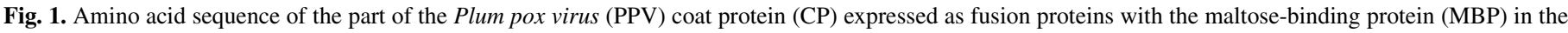

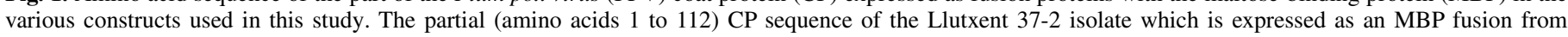

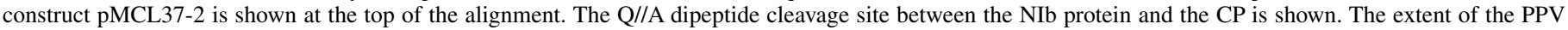

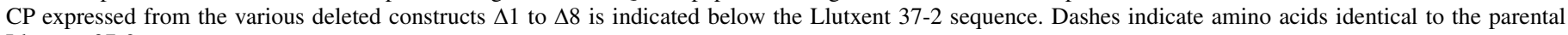
Llutxent 37-2 sequence. 
belonging to the PPV-D or PPV-M strains were cloned in frame with the MBP coding sequence in the pMal-C2 expression vector. The CP region present in these constructs corresponds to the 93-aa-long N-terminal variable part of the $\mathrm{CP}$ and to the first 19 aa of its conserved core. Upon IPTG induction, E. coli cells harboring the recombinant plasmids expressed a fusion protein of the expected size of $\approx 70 \mathrm{kDa}$ (54 kDa for the MBP plus $16.6 \mathrm{kDa}$ for the PPV NIb-CP fragment). The PPV-D or PPV-M fusion proteins could readily be detected in Western blots using either an MBP-specific rabbit polyclonal antiserum or either one of two polyclonal antisera raised against purified particles of isolates belonging to the $\mathrm{D}$ or $\mathrm{M}$ strains (Table 2). In induced control cells containing the nonrecombinant pMal-C2 vector, the MBP antiserum detected only the MBP protein while no reactivity was observed using the anti-PPV sera (Table 2).

The reactivity of the 24 MAbs toward the two fusion proteins was then similarly evaluated in Western blot assays. The results of a representative experiment, in which 5 MAbs were used to probe membrane strips on which the proteins extracts from cells containing either the pMCL37-2 construct or the nonrecombinant vector pMal-C2 had been transferred, are shown in Figure 2A. None of the MAbs showed reactivity toward proteins from cells containing the pMal-C2 vector. In contrast, in each case, the fusion protein was detected at the expected level (Fig. 2A). Additional protein bands of slightly faster electrophoretic mobility were also detected, probably representing partial degradation products or proteins that had been incompletely translated. Such faster migrating bands were also observed upon detection using the anti-MBP or anti-PPV polyclonal reagents (not shown).

In total, 20 of the 24 assayed MAbs detected the PPV-Dderived fusion protein from the pMCL37-2 construct (Table 2). The only MAbs that failed to react with this protein were MAbs 4F4, 3C6, and 4CB1 and MAb AL, which is known to be PPV-M specific (2). In contrast, only 13 of the 24 tested MAbs reacted with the PPV-M fusion protein expressed from the pMCM10
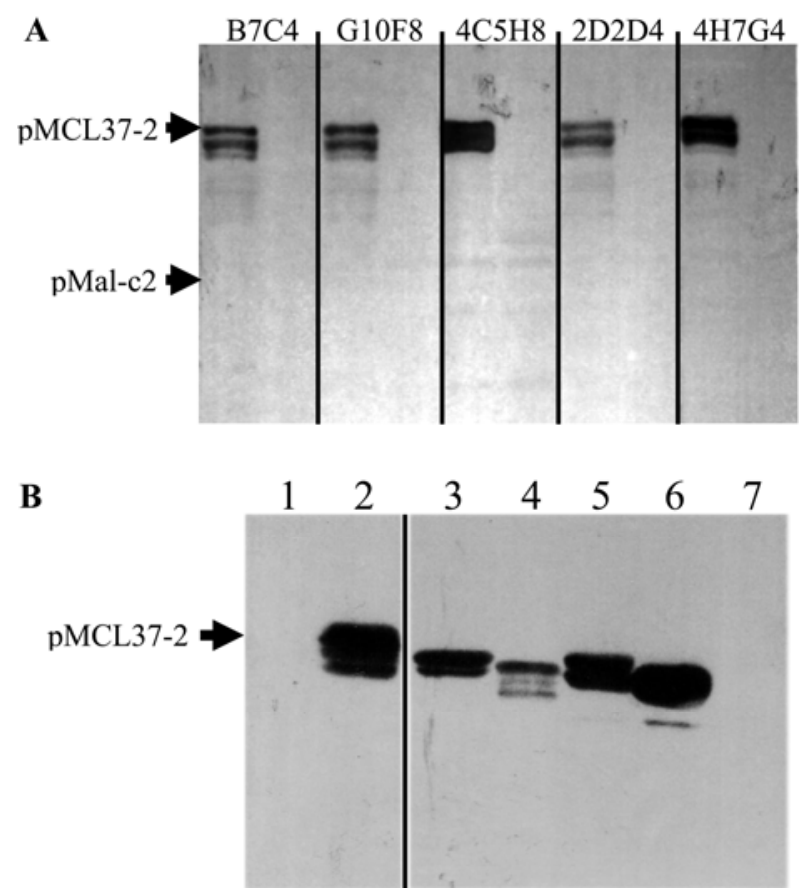

Fig. 2. Western blot detection of fusion proteins containing partial Plum pox virus (PPV) coat protein (CP) sequences using monoclonal antibodies (MAbs). A, Detection of the pMCL37-2 fusion protein, containing amino acids 1 to 112 of the PPV CP, using several MAbs. For each MAb indicated above the figure, equal amounts of induced Escherichia coli cells lysates were loaded on the gel. The left lane in each set corresponds to cells containing the pMCL372 construct, the right lane to cells containing the nonrecombinant pMal-C2 vector. The position of the two recombinant proteins as evaluated by Ponceau Red staining of the membrane is indicated on the left. B, Detection of fusion proteins containing deletions in the PPV CP part using the 4DB7 MAb. Equal amounts of induced $E$. coli cells lysates were loaded on each lane of the gel. Lane 1, nonrecombinant pMal-C2 vector; lane 2, pMCL37-2; lanes 3 to 7, constructs $\Delta 2$ to $\Delta 6$. The position of the pMCL37-2 protein is shown on the left.

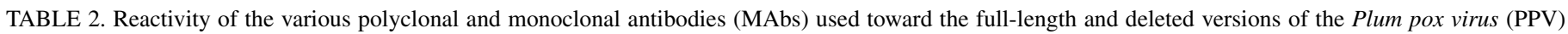
partial coat protein (CP) fusion proteins expressed in Escherichia coli ${ }^{\mathrm{a}}$

\begin{tabular}{|c|c|c|c|c|c|c|c|c|c|c|c|}
\hline \multirow[b]{2}{*}{ Reagent } & \multicolumn{9}{|c|}{ PPV-D fusion proteins ${ }^{b}$} & \multirow[b]{2}{*}{$\begin{array}{c}\text { pMCM10 } \\
(1-112)^{\mathrm{c}} \\
\end{array}$} & \multirow[b]{2}{*}{ pMal-C2 ${ }^{d}$} \\
\hline & $\begin{array}{c}\text { pMCL37-2 } \\
(1-112)\end{array}$ & $\begin{array}{c}\Delta 1 \\
(1-108)\end{array}$ & $\begin{array}{c}\Delta 2 \\
(1-102)\end{array}$ & $\begin{array}{c}\Delta 3 \\
(1-89)\end{array}$ & $\begin{array}{c}\Delta 4 \\
(1-71)\end{array}$ & $\begin{array}{c}\Delta 5 \\
(1-64)\end{array}$ & $\begin{array}{c}\Delta 6 \\
(1-48)\end{array}$ & $\begin{array}{c}\Delta 7 \\
(1-43)\end{array}$ & $\begin{array}{c}\Delta 8 \\
(1-30)\end{array}$ & & \\
\hline Anti-MBP & + & + & + & + & + & + & + & + & + & + & + \\
\hline PPV-D no. 100 & + & + & + & + & + & + & + & + & + & + & - \\
\hline PPV-M no. 137 & + & + & - & - & - & - & - & - & - & + & - \\
\hline 4DB12 & + & + & + & + & + & + & + & + & + & + & - \\
\hline B7C4 & + & - & + & - & + & + & + & + & + & + & - \\
\hline G10F8 & + & - & + & - & + & + & + & + & \pm & + & - \\
\hline 1EB6 & + & + & + & + & + & + & + & + & + & - & - \\
\hline 03 & + & + & + & + & + & + & + & + & + & - & - \\
\hline 08 & + & + & + & + & + & + & + & + & + & - & - \\
\hline 06 & + & + & + & + & + & + & + & + & - & - & - \\
\hline 04 & + & + & + & + & + & + & + & + & - & - & - \\
\hline 4DG5 & + & + & + & + & + & + & - & - & - & - & - \\
\hline 4DG11 & + & + & + & + & + & + & - & - & - & - & - \\
\hline 07 & + & + & + & + & + & + & - & - & - & + & - \\
\hline 4DB7 & + & - & + & + & + & + & - & - & - & + & - \\
\hline $4-11$ & + & + & + & + & - & - & - & - & - & + & - \\
\hline 5B-IVIA & + & + & + & - & - & - & - & - & - & + & - \\
\hline 4B1D5 & + & + & + & - & - & - & - & - & - & + & - \\
\hline 4H7G4 & + & + & + & - & - & - & - & - & - & + & - \\
\hline 4F4G11 & + & + & + & - & - & - & - & - & - & + & - \\
\hline 4C5H8 & + & + & + & - & - & - & - & - & - & + & - \\
\hline 2D2D4 & + & + & \pm & - & - & - & - & - & - & + & - \\
\hline 2D2D7 & + & \pm & - & - & - & - & - & - & - & - & - \\
\hline $\mathrm{AL}$ & - & - & - & - & - & - & - & - & - & + & - \\
\hline
\end{tabular}

a Three MAbs (4F4, 3C6, and 4CB1) failed to react against any of the fusion proteins assayed.

${ }^{b}$ Position on the PPV-D CP sequence of the CP amino acids present in each fusion protein are given in parentheses.

c PPV-M-specific fusion protein.

${ }^{\mathrm{d}}$ Maltose-binding protein (MBP) expressed from the nonrecombinant vector. 
construct (Table 2). However, the PPV-M-specific AL MAb readily detected this protein (Table 2 ).

Reactivity of the MAbs toward an ordered series of Cterminally truncated fusion proteins in the CP domain. A series of eight additional constructs was derived from the pMCL37-2 plasmid by recurrent exonuclease III deletion. The $\mathrm{p} \Delta 1$ to $\mathrm{p} \Delta 8$ vectors direct the expression of fusion proteins containing the first $108,102,89,71,64,48,43$, and 30 aa, respectively, of the PPV CP (Fig. 1). All eight fusion proteins could be successfully detected using the anti-PPV-D polyclonal antiserum no. 100. Remarkably, the anti-PPV-M no. 137 serum only detected the protein expressed from the construct with the smallest deletion, $\mathrm{p} \Delta 1$ (amino acids 1 to 108 of the PPV CP), while larger deletions abolished detection of the resultant fusion proteins (Table 2).

The reactivity of the 20 MAbs recognizing the pMCL37-2derived protein was then evaluated against all eight truncated proteins. The results obtained are summarized in Table 2 and the results of a representative experiment involving MAb 4DB7 are presented in Figure 2B. As can be seen, this MAb reacted with the proteins derived from the $\mathrm{p} \Delta 2$ to $\mathrm{p} \Delta 5$ (amino acids 1 to 64 ) constructions but completely failed to react with that derived from the $\mathrm{p} \Delta 6$ construct (amino acids 1 to 48 ). Given that the MAbs are very likely to recognize linear epitopes, the reactivity pattern toward the series of C-terminally truncated fusion proteins allows the positioning of the epitopes recognized by the various MAbs along the PPV CP sequence (Table 3). In total, the 20 MAbs assayed can be classified in at least six reactivity groups, based on their recognition pattern toward the truncated fusion proteins. Surprisingly, three MAbs (B7C4, G10F8, and 4DB7) failed to react with the $\Delta 1$ fusion protein and two of those (B7C4 and G10F8) also failed to react with the $\Delta 3$ fusion protein. Despite this, all three MAbs showed clear reactivity with the $\Delta 2$ protein as well as with proteins with more extensive deletions than the $\Delta 3$ one (Table 2; Fig. 2B). We have no explanation for this observation.

Identification of an amino acid mutation affecting the binding of the PPV-M-specific AL MAb. In the course of the production of the PPV-M fusion protein, two different cDNA clones were obtained and inserted in the pMal-C2 vector, yielding the pMCM5 and pMCM10 constructions. Parallel analysis of the corresponding proteins indicated that the pMCM5-derived one failed to react with the PPV-M specific AL MAb (result not shown). Sequencing of the PPV cDNA in the pMCM5 construct revealed only two point mutations compared with that in the pMCM10 construct, V74D and D79G (Fig. 3E). Analysis of the sequence of the $\mathrm{Ab}$-Tk isolate, which also fails to react with the AL MAb (7), showed three unique mutations in the same region: V61I, P63S, and P69D (Fig. 3E).

A full-length infectious PPV cDNA (PPVR/P306, with the CP of the PS isolate which belongs to the $\mathrm{M}$ strain) was mutagenized to incorporate the V74D mutation present in the pMCM5 cDNA. Analysis of the progeny of this recombinant clone, pGPPVPSV74D, confirmed the stability of the introduced mutation and demonstrated that it abolishes recognition by MAb AL (Fig. 3E).

\section{DISCUSSION}

The 24 MAbs used in this study had been developed independently in six different laboratories following immunization with purified virus particles and have all been selected for reactivity in TAS-ELISA assays. In all, 21 of the 24 MAbs reacted in western blots against fusion proteins containing amino acids 1 to 112 of the PPV CP. Of those, only 2D2D7 has a binding site that can be unambiguously mapped using the deleted fusion proteins to the part of the fusion protein corresponding to the conserved core of the $\mathrm{CP}$ (amino acids 93 to 112), while binding to this region is also a possibility for a further six MAbs (5BIVIA, 4B1D5, 4H7G4, 4F4G11, 4C5H8, and 2D2D4). Therefore, in total, a minimum of two-thirds of the reacting MAbs had binding sites in the variable $\mathrm{N}$-terminal region of the $\mathrm{CP}$, confirming the immunodominant nature of this region (43). Given the available information on the reactivity patterns of the various MAbs $(1,4,7)$ (Table 2; Fig. 3), it can be estimated that, at minimum, 10 epitopes are located in the $\mathrm{N}$-terminal region while, at minimum, 2 epitopes (potentially 4) are located in the conserved core part, further confirming this analysis. A similar picture is provided concerning the N-terminal CP region of PPV-W by Croft et al. (16), who identified a total of eight potential epitopes through the use of a panel of 10 MAbs obtained following immunization with a bacterially expressed $\mathrm{N}$-terminal fragment of the PPV-W CP.

Of the three MAbs which failed to react with the fusion proteins, one (4CB1) is known to have a specificity spectrum restricted to non-aphid-transmissible isolates (3), while another (4F4) is reported to have a very narrow specificity $(1,3)$. Therefore, it is not surprising that they failed to react with the pMCL37-2- or pMCM10-encoded proteins. Taken together, the

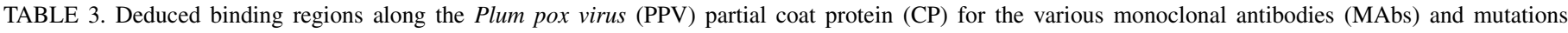
affecting this binding ${ }^{\mathrm{a}}$

\begin{tabular}{|c|c|c|c|c|}
\hline MAb & Binding region ${ }^{\mathrm{b}}$ & Restricted binding region $^{c}$ & Affected by mutations ${ }^{\mathrm{d}}$ & Potentially affected by mutations ${ }^{\mathrm{d}}$ \\
\hline 4DB12 & $1-30$ & $6-18$ & $\Delta 13-27, \mathrm{D} 11 \mathrm{G}$ & na \\
\hline B7C4, G10F8 & $1-30$ & $6-18$ & $\Delta 13-27, \mathrm{D} 11 \mathrm{G}$ & $\mathrm{D} 11 \mathrm{~N}, \mathrm{P} 15 \mathrm{~S}, \mathrm{I} 16 \mathrm{~N}$ \\
\hline $1 \mathrm{~EB} 6$ & $1-30$ & $4-12$ & D11G, D11N & na \\
\hline 03,08 & $1-30$ & $1-12$ & $\ldots$ & R4K, E7D \\
\hline 06,04 & $24-43$ & na & na & na \\
\hline 4DG5, 4DG11 & $42-64$ & $48-62$ & Q55R & T58I, K59R \\
\hline 07 & $42-64$ & na & na & na \\
\hline 4DB7 & $42-64$ & $42-52$ & L45P & F49L, P51S \\
\hline $4-11$ & $65-89$ & na & na & na \\
\hline 5B-IVIA & $83-102$ & $94-100$ & na & na \\
\hline 4B1D5, 4H7G4, 4F4G11, 4C5H8 & $83-102$ & na & na & 84A, 84S, L88V, N90R, 92R, R93K, S101T \\
\hline 2D2D4 & $83-102$ & na & na & na \\
\hline 2D2D7 & $95-108$ & na & na & S101T, 106S \\
\hline $\mathrm{AL}$ & na & $67-81$ & V74D, P69S & D79G \\
\hline
\end{tabular}

a Abbreviation: na = not applicable.

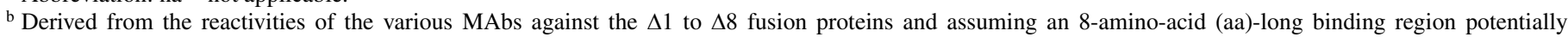
extending within the sequence of the largest nonreacting fusion protein.

${ }^{c}$ Derived assuming an 8-aa-long binding region incorporating mutations known to affect the binding of the monoclonal.

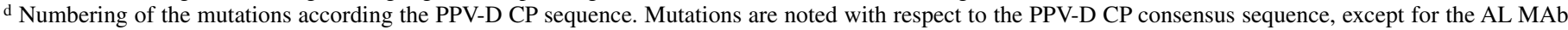
data, for which mutations are noted in respect to the PPV-M consensus, and for some mutations in the PPV-EA or PPV-SoC sequences, which are simply noted by the position in the alignment and the amino acids present in the divergent PPV isolates sequences. 
results obtained unambiguously show that the vast majority of the MAbs used in this study are able to recognize denatured PPV CP polypeptides and, therefore, are highly likely to recognize linear epitopes on this protein.
Linear epitopes are generally considered to have a size in the range of 5 to 7 aa (46), an evaluation confirmed by the good reactivities observed by Shukla et al. (43) using octapeptides and by the identification of two minimal epitopes in ZYMV CP of 5

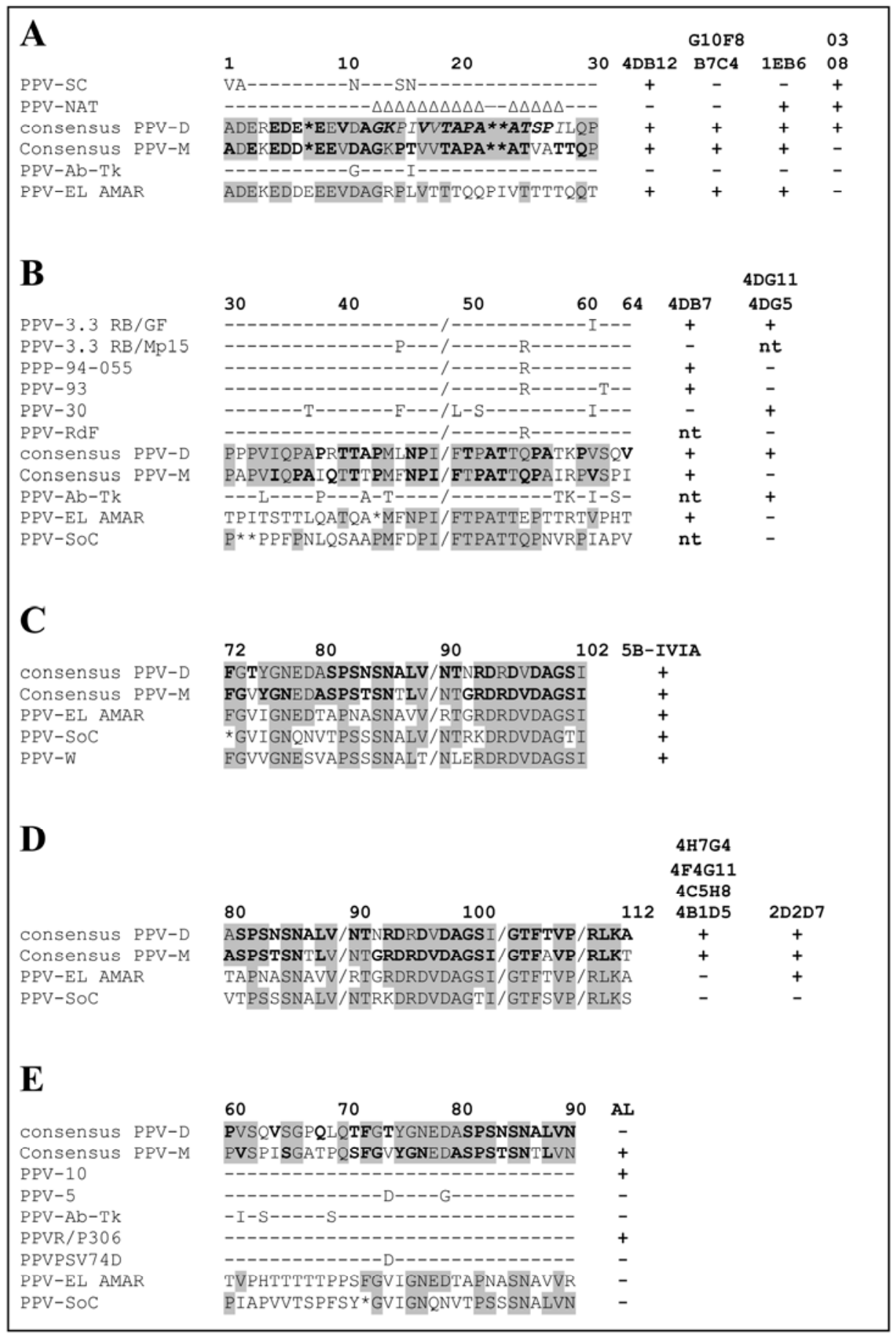

Fig. 3. Local alignment of Plum pox virus (PPV) coat protein (CP) sequences and reactivity of the isolates considered with various monoclonal antibodies (MAbs). Except for specific isolates, the sequences shown are consensus sequences for the PPV-D and PPV-M major phylogenetic groups. Amino acid positions fully conserved among all PPV-D or all PPV-M isolates are indicated in bold while amino acids conserved between the PPV-D and PPV-M consensus are shaded in gray. When applicable, amino acids identical between the PPV-El Amar, PPV-SoC, or PPV-W isolates and those conserved between the PPV-D and PPV-M consensus are also shaded. Isolates for which the PPV-D consensus is relevant appear above the PPV-D/PPV-M pair, while PPV-M-related and other non-PPV-D sequences appear below the PPV-M sequence. Amino acids of specific PPV-D or PPV-M isolates identical to the relevant consensus are indicated by dashes. Gaps introduced in the alignments are indicated by asterisks. The sequences are numbered on top; numbers refer to the PPV-D CP sequence. Reactivities with the various MAbs are indicated on the right. When applicable, the end of the CP part present in the relevant $\Delta 1$ to $\Delta 8$ construct is indicated by a slash in the alignment. A, Alignment of amino acids 1 to 30 , corresponding to the region present in the $\Delta 8$ construct. The deletion in the non-aphid-transmissible isolates is indicated by italics in the PPV-D consensus and by $\Delta$ signs in the PPV-NAT sequence. B, Alignment of amino acids 30 to 64 . Amino acids 30 to 48 are present in $\Delta 6$ while amino acids 30 to 64 are present in construct $\Delta 5$. C, Alignment of amino acids 72 to 102 , corresponding to constructs $\Delta 3$ (amino acids 1 to 89 ) and $\Delta 2$ (amino acids 1 to 102). D, Alignment of amino acids 80 to 112 , corresponding to constructs $\Delta 3$ (amino acids 1 to 89 ), $\Delta 2$ (amino acids 1 to 102 ), $\Delta 1$ (amino acids 1 to 108), or the complete pMCL37-2 (amino acids 1 to 112) sequence. E, Alignment of amino acids 60 to 90. 
and 7 aa, respectively (18). Integrating the possibility that epitopes may span the deletion sites of the $\Delta 1$ to $\Delta 8$ truncated fusion proteins and using a conservative size of 8 aa for an epitope, a tentative positioning of the binding sites recognized by the various MAbs is presented in Table 3.

For most of the MAbs used in this study, significant information about their reactivity toward a large panel of PPV isolates is available through the results of a PPV ring test performed in the frame of a COST- 88 concerted action (1) and in other workshops (4) or, for the 4DG5, 4DG11 (PPV-D-specific), and AL (PPV-Mspecific) MAbs, through the results reported by Candresse et al. (7). Additional sequence information was developed during the course of this work (Fig. 3) for two isolates, RdF (Rouge de Fournès, belonging to the PPV-D strain, accession no. EU729746) and Ab-Tk (Abricotier Turquie, belonging to the PPV-T strain, accession no. AY677115) (21,45), which had previously been shown to behave abnormally in MAb-based PPV strain-typing assays (7). Similarly, the reactivity of some the MAbs toward the PPV-Ab-Tk isolate was determined (Fig. 3).

For isolates differing in their MAbs reactivity pattern, local sequence comparisons of the binding region identified by their reactivity toward the series of fusion proteins are shown in Figure $3 \mathrm{~A}$ to D. These comparisons allow refinement of the epitope mapping and, in some cases, identification of key amino acids directly affecting the binding of the MAbs (Table 3). They also allow an estimation of the number of epitopes recognized in a given binding region.

For four of the six MAbs targeting the amino acid 1 to 30 region (as demonstrated with their reactivity with the $\Delta 8$ protein), no reactivity was detected toward the PPV Ab-Tk isolate (Fig. 3A), whereas these MAbs are known to broadly react with the vast majority of PPV-M and PPV-D isolates $(1,4,7)$. In the 1 to 30 region, the Ab-Tk isolate differs from the PPV-M consensus by two mutations, D11G and T16I, and the T16I mutation is observed in the PPV-D consensus, eliminating it as a candidate. Thus, the D11G mutation, which affects the first amino acid of the DAG triplet, is in all likelihood responsible for the lack of reactivity of MAbs 4DB12, G10F8, B7C4, and 1EB6 toward the $\mathrm{Ab}-\mathrm{Tk}$ isolate (Table 3). Mapping of the binding region of these MAbs around the DAG triplet is confirmed for MAbs 4DB12, G10F8, and B7C4 by their known lack of reactivity with the PPVNAT isolate $(1,4)$, a D strain isolate characterized by a large deletion encompassing amino acids 13 to 27 and, therefore, affecting the last $\mathrm{G}$ residue of the DAG triplet (Fig. 3A). Additional confirmation was obtained for MAbs 1EB6 and 4DB12 by PEPSCAN analysis, which revealed binding to three overlapping peptides sharing the EVDAGK (amino acids 9 to 14) region using a mixture of these two MAbs (M. R. Fernández-Fernández and J. A. García, unpublished results). Therefore, MAbs 1EB6, 03, and 08 , which are not affected by the amino acid 13 to 27 deletion found in PPV-NAT, have binding sites that can be mapped to the 1 to 12 region of the $\mathrm{CP}$, a region which can be further narrowed to positions 4 to 12 in the case of 1EB6, given the negative effect on its binding of mutations at position 11 of the $\mathrm{CP}$, again affecting the DAG triplet. In total, 20\% (4 of 20) of the MAbs recognizing the PPV N-terminal $\mathrm{CP}$ fusions have a binding site including amino acids of the DAG triplet. Interestingly, none of the MAbs analyzed by Croft et al. (16) appears to have reactivity toward this region, a fact that could potentially be linked to the immunization strategy used to obtain these MAbs, which involved a bacterially produced CP N-terminal fragment. Identification of MAbs with a similar specificity, including an intact DAG triplet, had previously been reported but with the conclusion that a conformational rather than a linear epitope was involved (30).

For the 4DB7, 4DG5, and 4DG11 MAbs, which are characterized by recognition of the $\Delta 5$ but not of the $\Delta 6$ protein, closely related PPV isolates showing differential reactivity are also available (Fig. 3B). In the case of 4DB7, reactivity is lost in isolate PPV $3.3 \mathrm{RB} / \mathrm{Mp} 15$, a variant initially selected upon individual aphid transmission (1). This isolate shows two mutations in the binding region identified, L45P near the end of the $\Delta 5$ protein and Q55R in the region specific of the $\Delta 6$ protein. However, several isolates recognized by MAb 4DB7 also possess the Q55R mutation (Fig. 3B), identifying the L45P mutation as the one responsible for the lack of reactivity of the PPV 3.3 $\mathrm{RB} / \mathrm{Mp} 15$ isolate. Further confirmation of this identification is provided by the sequence of another PPV-D isolate, PPV-30 (17), which is not recognized by 4DB7 and shows an L45F mutation affecting the same amino acid. PEPSCAN analyses have confirmed amino acids 45 to 52 as the target of the 4DB7 MAb (M. R. Fernández-Fernández and J. A. García, unpublished data).

In the case of the two PPV-D-specific MAbs, 4DG5 and 4DG11, several isolates belonging to the D strain but failing to react had been identified (7). All of these are characterized by the same Q55R mutation. In addition, Candresse et al. (7) have also shown that, despite belonging to the $\mathrm{M}$ strain, the Ab-Tk isolate was detected by the PPV-D-specific MAbs. Sequence analysis around the 55 position shows that it is unique among PPV-M isolates in having a double $\mathrm{I} 58 \mathrm{~T}$ and $\mathrm{R} 59 \mathrm{~K}$ mutation which makes it identical to the PPV-D consensus sequence (Fig. 3B).

The 5B-IVIA MAb is the only PPV-specific MAb known to recognize all PPV isolates identified to date $(1,4,7)$. Its reactivity even extends to the widely divergent PPV-EA (48), PPV-SoC (37), and PPV-W (29) strains. It reacts with the $\Delta 2$ but not with the $\Delta 3$ fusion protein (Table 2), positioning its binding site around amino acids 83 to 102 (assuming an epitope of eight amino acids), in contrast to a previously erroneous mapping in the amino acid 72 to 89 region (10). In this region, a single protein motif is fully conserved between the PPV-D and PPV-M consensus and the sequences of the divergent isolates (Fig. 3C). It is the DRDVDAG sequence, corresponding to positions 94 to 100 of the PPV-CP. This mapping is confirmed by analyses showing that PEPSCAN peptides sharing the RDRD sequence (amino acids 93 to 96) are recognized by the 5B-IVIA MAb (M. R. FernándezFernández and J. A. García, unpublished results). In this context, it is noteworthy that the RDRD sequence has been successfully used as an epitope tag recognized by the 5B-IVIA by Cervera et al. for the tagging of heterologous proteins (11). Several other MAbs obtained at INRA Bordeaux (4H7G4, 4F4G11, 4C5H8, and $4 \mathrm{~B} 1 \mathrm{D} 5$ ) have the same reactivity pattern as 5B-IVIA toward the fusion proteins (Table 2) but fail to react with the El Amar and SoC isolates (Fig. 3D). Mutations L88V or N90T in the case of the El Amar isolate and R93K or S101T in the case of the SoC isolate are likely to be responsible for the lack of reactivity of these isolates.

Using a PEPSCAN analysis and polyclonal antisera, Fernández-Fernández et al. (20) identified 13 PRS on the PPV CP. Six of those (four in the N-terminal region and two in the core) fall in the region analyzed in the study reported here. Most of the binding sites identified here are compatible with the PRS. However, it is noteworthy that close to one-third (6 of 20) of the reacting MAbs analyzed here and one-fifth (2 of 10) of the MAbs analyzed by Croft et al. (16) can be mapped to a minimal 1 to 18 region which was not recognized as a PRS using polyclonal antisera (20).

Finally, mutagenesis of a full-length PPV infectious clone allowed the unambiguous demonstration that a V74D mutation abolishes the binding of the only known PPV-M-specific MAb (MAb AL) $(2,10)$. The P69S mutation in isolate Ab-Tk is likely to explain the lack of reactivity of this isolate with the AL MAb. Assuming an 8-aa length of the epitope, these indications allow a tentative positioning of the AL-binding region to within amino acids 67 to 81 of the CP.

The combined use of E. coli-expressed PPV CP fragments and sequence comparisons between isolates differing in their reactivities has allowed a tentative mapping of 14 epitopes recognized 
by 21 MAbs, including the widely used 5B-IVIA (polyvalent), AL (PPV-M-specific), 4DG5, and 4DG11 (PPV-D-specific) MAbs. Further refining of the binding positions identified would require additional work using different approaches, such as PEPSCAN $(18,43)$ or mutagenesis of infectious clones. The results obtained provide a comprehensive vision which will be useful for the understanding of abnormal reaction patterns with widely used detection reagents and which could form the basis for the development of new detection or typing MAbs, using peptide immunization (15) targeting precise immunogenic regions of the PPV CP or in the development of epitope tags that could be of use for the recognition of any recombinant protein (11).

\section{ACKNOWLEDGMENTS}

We thank P. Gugerli (RAC Changins, Switzerland) for providing MAb 4-11, G. Pasquini and M. Barba (ISPAVE, Roma, Italy) for MAbs B7C4 and G10F8, J. B. Quiot and S. Dallot for making available some PPV CP sequences before publication, and F. Rafia for her contribution to initial work with deleted PPV CP fusion proteins. Work of P. Saenz and J. A. García was supported by grant BIO2004-02687 from the Spanish Ministerio de Educación y Ciencia (MEC); and work of M. T. Gorris and M. Cambra was supported by grant AGL2005-01546 from MEC and by AMR Lab Consultants (Barcelona, Spain), resulting in patent P201000347 of March 2010.

\section{LITERATURE CITED}

1. Asensio, M. 1996. El virus de la Sharka (plum pox virus): Caracterizacion, diagnóstico y detección mediante anticuerpos monoclonales especificos. Ph.D. thesis, Universidad Politécnica de Valencia (UPV), Valencia, Spain.

2. Boscia, D., Zeramdini, H., Cambra, M., Potere, O., Gorris, M. T., Myrta, A., Di Terlizzi, B., and Savino, V. 1997. Production and characterization of a monoclonal antibody specific to the $M$ serotype of plum pox potyvirus. Eur. J. Plant Pathol. 103:477-480.

3. Cambra, M., Asensio, M., Gorris, M. T., Pérez, E., Camarasa, E., García, J. A., Moya, J. J., López-Abella, D., Vela, C., and Sanz, A. 1994. Detection of plum pox potyvirus using monoclonal antibodies to structural and non-structural proteins. EPPO Bull. 24:569-577.

4. Cambra, M., Boscia, D., Myrta, A., Plakovics, L., Navratil, M., Barba, M., Gorris, M.T., and Capote, N. 2006. Detection and characterization of Plum pox virus: Serological methods. EPPO Bull. 36:254-261.

5. Cambra, M., Capote, N., Myrta, A., and Llacer, G. 2006. Plum pox virus and the estimated costs associated with Sharka disease. EPPO Bull. 36:202-204.

6. Candresse, T., and Cambra, M. 2006. Plum pox virus strains or types: Historical perspective and current status. EPPO Bull. 36:239-246.

7. Candresse, T., Cambra, M., Dallot, S., Lanneau, M., Asensio, M., Gorris, M. T., Revers, F., Macquaire, G., Olmos, A., Boscia, D., Quiot, J. B., and Dunez, J. 1998. Comparison of monoclonal antibodies and polymerase chain reaction assays for the typing of isolates belonging to the D and $\mathrm{M}$ serotypes of plum pox potyvirus. Phytopathology 88:198-204.

8. Candresse, T., Macquaire, G., Lanneau, M., Bousalem, M., Quiot-Douine, L., Quiot, J. B., and Dunez, J. 1995. Analysis of plum pox potyvirus variability and development of strain-specific PCR assays. Acta Hortic. 386:357-369

9. Candresse, T., Macquaire, G., Lanneau, M., Bousalem, M., Wetzel, T., Quiot-Douine, L., Quiot, J. B., and Dunez, J. 1994. Detection of plum pox potyvirus and analysis of its molecular variability using immunocapturePCR. EPPO Bull. 24:585-594.

10. Candresse, T., Rafia, F., Cambra, M., Asensio, M., Navratil, M., García, J. A., Boscia, D., Barba, M., and Dunez, J. 1998. Characterization of Plum pox virus coat protein epitopes using fusion proteins expressed in E. coli. Acta Hortic. 472:461-467.

11. Cervera, M., Esteban, O., Gil, M., Gorris, M. T., Martínez, M. C., Pena, L., and Cambra, M. 2010. Transgenic expression in citrus of single-chain antibody fragments specific to Citrus tristeza virus confers virus resistance. Trangenic Res. doi:10.1007/s11248-010-9378-5.

12. Cervera, M. T. 1993. Análisis de determinantes de patogenicidad del virus de la sharka. Estudio molecular del aislado Ph.D. thesis, Universidad Autónoma de Madrid.

13. Cervera, M. T., Riechmann, J. L., Martin, M. T., and García, J. A. 1993. 3'-Terminal sequence of the plum pox virus PS and o6 isolates: Evidence for RNA recombination within the potyvirus group. J. Gen. Virol. 74: 329-334.
14. Chikh Ali, M., Maoka, T., and Natsuaki, K. T. 2007. A point mutation changes the serotype of a Potato virus $Y$ isolate; genomic determination of the serotype of PVY strains. Virus Genes 35:359-367.

15. Crescenzi, A., d'Aquino, L., Nuzzaci, M., Ostuni, A., Bavoso, A., Comes, S., De Stradis, A., and Piazzolla, P. 1997. Production of strain specific antibodies against a synthetic polypeptide corresponding to the $\mathrm{N}$ terminal region of the plum pox potyvirus coat protein. J. Virol. Methods 69:181-189.

16. Croft, H., Malinowski, T., Krizbai, L., Mikec, I., Kajic, V., Reed, C., Varga, A., and James, D. 2008. Use of Luminex xMAP-derived Bio-Plex bead-based suspension array for specific detection of PPV-W and characterization of epitopes on the coat protein of the virus. J. Virol. Methods 153:203-213.

17. Dallot, S., Labonne, G., Quiot-Douine L., Boeglin M., Candresse T., and Quiot, J. B. 1998. Peculiar plum pox potyvirus D-populations are epidemic in peach trees. Acta Hortic. 472:355-365.

18. Desbiez, C., Gal-On, A., Raccah, B., and Lecoq, H. 1997. Characterization of epitopes on zucchini yellow mosaic potyvirus coat protein permits studies on the interaction between strains. J. Gen. Virol. 78:20732076.

19. Dunez, J., and Sutic, D. 1988. Plum pox virus. Pages 44-46 in: European Handbook of Plant Diseases. I. M. Smith, J. Dunez, R. A. Lelliot, D. H. Philips, and S. A. Archer, eds. Blackwell Scientific Publications, Oxford, UK.

20. Fernández-Fernández, M. R., Martínez-Torrecuadrada, J. L., Roncal, F., Domínguez, E., and García, J. A. 2002. Identification of immunogenic hot spots within plum pox potyvirus capsid protein for efficient antigen presentation. J. Virol. 76:12646-12653.

21. Glasa, M., and Candresse, T. 2005. Partial sequence analysis of an atypical Turkish isolate provides further information on the evolutionary history of Plum pox virus (PPV). Virus Res. 108:199-206.

22. Glasa M., Marie-Jeanne, V., Moury, B., Kudela, O., and Quiot, J. B. 2002. Molecular variability of the P3-6K1 genomic region among geographically and biologically distinct isolates of Plum pox virus. Arch. Virol. 147:563-575.

23. Glasa, M., Palkovics, L., Kominek, P., Labonne, G., Pittnerova, S., Kudela, O., Candresse, T., and Subr, Z. 2004. Geographically and temporally distant natural recombinant isolates of Plum pox virus (PPV) are genetically very similar and form a unique PPV subgroup. J. Gen. Virol. 85:2671-2781.

24. Hammond, H., and Hammond, R. W. 1989. Molecular cloning, sequencing and expression in Escherichia coli of the bean yellow mosaic virus coat-protein gene. J. Gen. Virol. 70:1961-1974.

25. Hammond, J., Jordan, R. L., and Kamo, K. K. 1990. Use of chimeric coat protein constructs and deletion mutants to examine potyvirus structure and coat protein mediated resistance. (Abstr.) Phytopathology 80:1018.

26. Herlitze, S., and Koenen, M. 1990. A general and rapid mutagenesis method using polymerase chain reaction. Gene 91:143-147.

27. Hewish, D. R., Xiao, X. W., Mishra, A., Gough, K. H., and Shukla, D. D. 1993. Characterization and epitope analysis of monoclonal antibodies to clover yellow vein and Johnsongrass mosaic potyviruses. Arch. Virol. 133:127-141.

28. Hilgert, I., Cikanek, D., Kristofova, H., Karesova, R., and Navratil, M. 1993. Monoclonal antibodies suitable for plum pox virus determination. Hybridoma 12:215-220.

29. James, D., and Varga, A. 2005. Nucleotide sequence analysis of Plum pox virus isolate W3174: Evidence of a new strain. Virus Res. 110:143-150.

30. Jayaram, C., van Deusen, R. A., Eggenberger, A. L., Schwabacher, A. W., and Hill, J. H. 1998. Characterization of a monoclonal antibody recognizing a DAG-containing epitope conserved in aphid transmissible potyviruses: Evidence that the DAG motif is in a defined conformation. Virus Res. 58:1-11.

31. Jordan, R. L. 1992. Potyviruses, monoclonal antibodies and antigenic sites. Arch. Virol. (Suppl.) 5:81-95.

32. Kirschman, J. A., and Cramer, J. H. 1988. Two new tools: Multi-purpose cloning vectors that carry kanamycin or spectinomycin/streptomycin resistance markers. Gene 68:163-165.

33. Kundu, A. K., Ohshima, K., and Sako, N. 1998. Comparison of coat protein epitopes of two zucchini yellow mosaic virus isolates. Acta Virol. 42:167-173.

34. López-Moya, J. J., Sanz, A., Cambra, M., Gorris, M. T., Anaya, C., Miguet, J. G., Cortés, E., and López-Abella, D. 1994. Production and characterization of monoclonal antibodies to plum pox virus and their use in the differentiation of Mediterranean isolates. Arch. Virol. 135:293-304.

35. Myrta, A., Potere, O., Boscia, D., Candresse, T., Cambra, M., and Savino, V. 1998. Production of a monoclonal antibody specific to the El Amar strain of Plum pox virus. Acta Virol. 42:248-250.

36. Myrta, A., Potere, O., Crescenzi, A., Nuzzaci, M., and Boscia, D. 2000. Production of two monoclonal antibodies specific to cherry strain of Plum pox virus. J. Plant Pathol. 82:95-103. 
37. Nemchinov, L., and Hadidi, A. 1996. Characterization of the sour cherry strain of plum pox virus. Phytopathology 86:575-580.

38. Nemchinov, L., Hadidi, A., Maiss, E., Cambra, M., Candresse, T., and Damsteegt, V. 1996. Sour cherry strain of plum pox potyvirus (PPV): Molecular and serological evidence for a new subgroup of PPV strains. Phytopathology 86:1215-1221.

39. Olmos A., Cambra M., Dasi M. A., Candresse T., Esteban O., Gorris M. T., and Asensio M. 1997. Simultaneous detection and typing of plum pox potyvirus (PPV) isolates by heminested-PCR and PCR-ELISA. J. Virol. Methods 68:127-137.

40. Roy, A. S., and Smith, I. M. 1994. Plum pox situation in Europe. EPPO Bull. 24:515-523.

41. Sáenz, P., Cervera, M. T., Dallot, S., Quiot, L., Quiot, J. B. Riechmann, J. L., and García, J. A. 2000. Identification of a pathogenicity determinant of Plum pox virus in the sequence encoding the $\mathrm{C}$-terminal region of protein P3+6K 1 . J. Gen. Virol. 81:557-566.

42. Shukla, D. D., Strike, P. M., Tracy, S. L., Gough, K. H., and Ward, C. W. 1988. The $\mathrm{N}$ and $\mathrm{C}$ termini of the coat proteins of potyviruses are surfacelocated and the N-terminus contains the major virus-specific epitopes. J. Gen. Virol. 69:1497-1508.

43. Shukla, D. D., Tribbick, G., Mason, T. J., Hewish, D. R., Geysen, H. M., and Ward, C. W. 1989. Localization of virus-specific and groupspecific epitopes of plant potyviruses by systematic immunochemical analysis of overlapping peptide fragments. Proc. Natl. Acad. Sci. USA $86: 8192-8196$

44. Thompson, J. D., Gibson, T. J., Plewniak, F., Jeanmougin, F., and Higgins, D. G. 1997. The Clustal X windows interface: Flexible strategies for multiple sequence alignment aided by quality analysis tools. Nucleic Acids Res. 24:4876-4882.

45. Ulubas Serce, C., Candresse, T., Svanella-Dumas, L., Krizbai, L., Gazel, M., and Caglayan, K. 2009. Further characterization of a new recombinant group of Plum pox virus isolates, PPV-T, found in orchards in the Ankara province of Turkey. Virus Res. 142:121-126.

46. Van Regenmortel, M. H. 1989. Structural and functional approaches to the study of protein antigenicity. Immunol. Today 10:266-272.

47. Wetzel, T., Candresse, T., Macquaire, G., Ravelonandro, M., and Dunez, J. 1992. A highly sensitive immunocapture polymerase chain reaction method for plum pox potyvirus detection. J. Virol. Methods 39:27-37.

48. Wetzel, T., Candresse, T., Ravelonandro, M., Delbos, R. P., Mazyad, H., Aboul-Ata, E. E., and Dunez, J. 1991. Nucleotide sequence of the $3^{\prime}$ terminal region of the RNA of the El Amar strain of plum pox potyvirus. J. Gen. Virol. 72:1741-1746. 